\title{
Measuring the Effect of Organization Structure on the Institution' Performance Efficiency: Empirical Study, Elicited from the Reality of the Palestinian Ministry of Education and Higher Education
}

\author{
Asri Ahmad Sammoudi ${ }^{1}$ \\ ${ }^{1}$ Department of business administration, Arab American University- Jenin, Palestine. \\ Correspondence: Asri Ahmad Sammoudi, Department of business administration, Arab American University- Jenin, \\ Palestine, P.O. BOX 240, Jenin - West Bank, Palestine. Tel: 00970592835454.
}

Received: July 27, 2016

Accepted: August 8, 2016

Available online: September 7, 2016

doi:10.11114/ijsss.v4i10.1771

URL: http://dx.doi.org/10.11114/ijsss.v4i10.1771

\begin{abstract}
This paper comes to measure the effect of organization structure on the institution' performance efficiency: empirical study, elicited from the reality of the Palestinian ministry of education and higher education. This study is based on the descriptive and analytical approach. The descriptive and analytical approach adopts explaining the phenomena depending on its realty, and considers analyzing and describing the phenomena accurately. The study population consists of 400 employees of the working staff at the Ministry of Education and Higher Education in Palestine including academics and administrators. Similarly, the study sample includes the administrative staff that has a direct link to the formulation and implementation of policies and procedures by the Ministry of Education and Higher Education in Palestine, in the city of Ramallah. This sample represents a random sample that includes 50 employees and rates $\% 12.5$ of the study population. However, the following statistical models are employed so as to test the hypotheses of this study. These models are: Descriptive Statistics, Cronbach Alpha Coefficient, and T Test. The following are the most important results of this study. (1) The planning procedures of the academic and administrative functions suffer from weaknesses and deficiencies regarding the current and future programs. (2) educational institutions of both the public and private sectors in Palestine. (3) There is a lack of enough cooperation in organizing the educational programs for various educational stages starting from the primary stage and ending with the university graduation. (4) There is a lack of enough follow-up and controlling regarding the implementation of various academic and administrative programs, which leads to a deviation in achieving the drawn goals and plans. (5) There is a lack of sufficient and organized evaluation through which we can recognize the advancement in achieving the drawn goals; as well as the decisions and functions are being corrected and revised in order to serve the organization and its drawn goals. (6) There is a lack of sufficient coordination regarding the educational outputs between the academic and educational institutions of both sectors the public and the private. Based on the previous findings, the study comes out with the following recommendations: (1) The Ministry of Education and Higher Education in Palestine is advised to focus on the importance of increasing the coordination between the educational institutions and the governmental organizations regarding the planning and the implementation of the current and the future lesson planning programs. (2) It highly recommends the government to increase its role in terms of planning, implementation, supervision, and reviewing the different educational and academic programs.
\end{abstract}

Keywords: organization structure, institution' performance efficiency, Palestinian ministry of education and higher education

\section{Introduction}

There is no doubt that the organizational structure is considered as the foundation stone of the business success because of its remarkable standing in particular in enhancing the institutional performance. Hence, the importance of the organization structure is determined through the distribution of powers, hierarchy of authorities, responsibilities, activities, distribution of roles and tasks so as to achieve the institution' desired objectives. In fact, the organization structure represents the major elements and components of the institutions its effect on implementing the policies, procedures regulation; as well as the distribution of the vested powers and hierarchy of authorities, which leads to achieve the objectives of the institution. 
Generally speaking, the organization structure represents the organizational hierarchy that determines the authorities, responsibilities, and activities that aim at achieving the desired objectives of the institution. Thus, the organization structure determines and divides the responsibilities, powers and functions, activities and authorities at various administrative hierarchies. In particular, the firm success depends basically on the good planning that designed for offering the administrative needs of the organization; as well as building an organizational structure based on the implementation of the administrative plans, official procedures and the distribution of tasks and powers in a way that leads to achieve the drawn goals of the institution.

However, the key objective of this study explains the efficiency and effectiveness of the organizational structure at the Ministry of Education and Higher Education in Palestine from several aspects. These aspects include considering the importance of working within scientific bases in dealing with the followed procedures, decisions, management practices; as well as applying the administrative practices rationally. This also includes the availability of professional working staff with high experience. The study explains the importance of transparency in the work; as well as following the accurate procedures when any decision is made by the management. Another important aspect is the evaluation processes and controlling that must be done in accordance with the rules and controlling requirements. Hence, the aforementioned six aspects are to be linked with the performance at the Palestinian Ministry of Education and Higher Education (MOHE). That is because of their significant role in enhancing the performance success at any institution.

Recently, the educational sector in Palestine has witnessed a remarkable development; where the educational indicators show that there is a general awareness regarding this vital sector. However, the most important basis of these developments, for instance, is the existence of the equal opportunity between male and female students' enrollment at all school stages; as well as the university education field. Statically, statistical data of 2010 show that about \% 44.7 of the youth are registered at different educational levels. These statistics also explain that the ages of those youth are until 29 years, which indicates high percentage of those who have completed the first Bachelor degree at the university education where males rate \%8.1. In contrast, the females' level rises when compared to the males within the same age group. It rates \%10.0 (Palestinian Central Bureau of Statistics, 2012).

Therefore, this study discusses an important topic on the business management, wherein the organizational structure plays a basic role in the institution functions. In other words, the organizational structure unites the authorities, responsibilities, tasks and activities, making decisions; in addition, to implementing the business procedures inside and outside the organization through the formal and informal relations that support and strengthen the official business, or that of which may endanger achieving the objectives of the organization.

Precisely, this study comes to explore and investigate the data of the study sample, which represents a certain sample of the working staff at the Palestinian Ministry of Education and Higher Education of different administrative levels. Thus, the data are gathered from various sources and references so as to enrich the topic of the study; and then to be presented with the results depending on the statistical analysis and data registry. The results also will be introduced; as well as making suggestions and recommendations on the effect of organizational structure on the institutional performance efficiency from the reality of the Palestinian Ministry of Education and Higher Education.

\section{Theoretical Framework}

The following are some theoretical concepts related to the study topic:

\subsection{The Concept of Organizational Structure}

There are several definitions about the organizational structure concept, for instance, it was defined by (Ebert and Griffin, 2009) "as the institution administrative hierarchy, stating the positions hierarchy, and the relationships between the individuals. He also explains the authorities' hierarchy and responsibility in the organization; where the observer to any organization can recognize its units, departments and its authority. As well, (Al-Amian, 2002) explains that "the organizational structure is the official mechanism by which the organization is managed by defining the hierarchy of authorities and communications between the executives and employees. It is also the authority, accountability and the system of relations between the organizational units that determine the shape and nature of the required work at the organization. Moreover, (Akili, 1996) defines the organizational structure as a framework that illustrates the administrative divisions that make up the organization; where it is arranged in the form of hierarchy levels. It takes the shape of a pyramid that linked with the official authorities to provide instructions and directions from the highest level or lower in which the decision-making, authority and responsibility are explained. In addition, (Al-Heil'lo, 1985) defines it as the internal construction of the organization, which includes all of the organizational aspects and divisions, where the structure illustrates the relationship between these divisions in terms of the effect of each one, its components from the lower divisions, its authority, and the responsibility of each one. 


\subsection{Organizing}

Organizing is an administrative function that designs the framework in order to regulate the function of a certain group of individuals to achieve specific goals. "This requires determining the number and type of activities needed to achieve these goals; as well as determining the individuals and those who are responsible for implementing the assigned activities. Another requirement is determining the authority relations with those individuals in terms of functions, responsibilities and powers" (Akili, 1996). However, the organizing is considered as a second administrative function and one of the most important management issues. Thus, "the management is called the science of organizing management". The organizing here means every action tends to regulate and determine the functions of the organization like the financial functions, marketing, and determining its management departments such as (the financial management and marketing management). Hence, the relation among these components altogether is determined through determining the authority and responsibility, delegation, centralization and decentralization scope; in addition to the supervision hierarch and other items that aim at achieving the specified goals" (Al-Heil'lo, 1985).

It is worth mentioning that the organizing is also considered as one of the administrative functions, which include the distribution of tasks and authority on human resources under the director supervision and within specific organizational structure.

Hence, organizing is employed fundamentally as the base of the organizational structure procedures. Add to this the role of the organizing process in determining the functions at the departments and divisions and their boards and committees in the company. In addition, the organizing determines the tasks and the level of the granted powers and responsibilities; as well as distributing the administrative ranks, and determining the centralization and decentralization. To be brief, the organizing is the foundation stone that shapes the organizational structure (Ebert and Griffin, 2009).

Likewise, (Qunswa and Rasheed, 1984; Al-Jawhari, 1985; Akili, 1996) state that' 'the organizational structure is one of the most important elements of the organization success, in which it illustrates graphically the nature and type of the organizational structure of the organization. In addition, it illustrates the organization 'internal structure, divisions, sections, and the distribution of powers and responsibilities".

\section{Literature Review}

The previous studies are explained as in the following:

The purpose of (Iljins, 2016) paper is to investigate the impact of organizational culture on organizational climate in the process of change. After exploring the impact of organizational culture on organizational climate through distinguished culture's factors, article examines the importance of these factors and, what is more, presents the case study analyzing organizational culture determinants impact on organizational climate based on the research of two Latvian medium-sized companies. The results of the research confirmed that during the period of changes organizational culture has an impact on organizational climate through specific factors. Theoretical model how change of organizational culture impacts organizational climate is developed.

The paper of (Laforet, 2016) comes to examine the effects of organizational culture (OC) on organizational innovation performance (OIP) in family small and medium-sized enterprises (SMEs). It seeks to establish the type of culture that lead to high innovation performance in family firms. A postal survey of family SMEs across sectors in the UK is conducted. The study employs multiple regression analyses to test which family business culture has an effect on OIP. Among the family business cultures tested are an external cultural orientation, a flexible and open OC as well as an organizational climate based on open communication and trust, the founder culture, and a long-term cultural orientation. The findings show that a paternalistic and founder culture type do not have a positive effect on family firm innovation performance, but an entrepreneurial-like culture does, i.e. one that is externally oriented, flexible, proactive (refer to an open culture) and long-term oriented. Similarly, an inward focus culture such as, the founder culture impedes innovation; while an outward focus culture such as, an external orientation culture has a positive effect on family firm innovation performance. This study makes valuable contributions to the understanding of theory and practices of innovation in family businesses. It provides future research directions

The paper of (Hakim, 2015) aims to analyze and determine the influence of organizational culture on organizational commitment and employee performance as well as the influence of organizational commitment to employee performance. The approach used is causality between the variables, whereas sampling techniques using the census method with the number of respondents targeted 115 employees. All the variables measured using indicators variables, and analytical methods used are Structural Equation Model (SEM). The results showed that organizational culture has a positive and significant impact on organizational commitment and employee performance. It was also found that organizational commitment has a positive and significant impact on employee performance, and organizational commitment has a significant role as a mediating variable between organizational cultures with employee performance. 
These findings give meaning that, to improve employee performance it is necessary to increase organizational culture and organizational commitment.

The paper of (Mousavi, 2015) shows that many researchers devoted numerous articles to the organizational culture, relatively few articles have been contributed to culture and performance research. The purpose of this study is to shed light on the role of organizational culture on performance. To achieve this goal and in order to measure organizational culture, Denison organizational culture model was used. The components of this model are: involvement, consistency, adaptation and mission. For performance evaluation survey, EFQM model was used. This model surveys performance in two different areas of enablers and results. The conceptual model of the research was tested by Structural Equation Modeling. Some university professors and Bank experts confirmed the Validity of questionnaires, and the reliability was tested by Cronbach alpha coefficient. Managers of the bank branches filled the performance evaluation questionnaires, and employees filled organization culture questionnaires. The results showed that between the components of organizational culture, just involvement and adaptability affect the performance of banks. The remaining components have indirect effect on the performance.

The study of ( Shahzad et al., 2012) comes to define and measure organizational culture and its impact on the organizational performance, through an analysis of existing empirical studies and models link with the organizational culture and performance. The objective of this article is to demonstrate conceptualization, measurement and examine various concepts on organization culture and performance. After analysis of wide literature, it is found that organizational culture has deep impact on the variety of organizations process, employees and its performance. This also describes the different dimensions of the culture. Research shows that if employee are committed and having the same norms and value as per organizations have, can increase the performance toward achieving the overall organization goals. Balance Scorecard is suggested tool to measure the performance in the performance management system. More research can be done in this area to understand the nature and ability of the culture in manipulating performance of the organization. Managers and leaders are recommended to develop the strong culture in the organization to improve the overall performance of the employees and organization.

The paper of (Aktas et al., 2011) shows that in today's increasing competitive conditions, reaching desired organizational efficiency level attracts both academician's and practitioners' interest much more. The factors influencing organizational efficiency are examined with highly increasing importance. Considering organizational culture as one of the factors, the effect of the types of organizational culture on organizational efficiency is questioned. The determining effect of organizational environment getting complex on the strategy that enable achieving organizational level can play a significant role on the relationship between organizational culture and organizational efficiency. The individual effect of the organizational leaders on the efficiency strategies is viewed in terms of their values. In this study, relationship between organizational culture and organizational efficiency and the effect of stability or variability of internal and external environment on this relation are investigated. Besides, the values of self-direction, stimulation, power that leaders have are researched. 40 top managers/organizational founders are selected for sampling in health sector. Questionnaire method is utilized for gathering data. The findings show that organizational culture types are related to some organizational efficiency dimensions. The stability or variability of internal and external organizational environment and the top manager's values (self-direction and stimulation) play a moderator role on this relationship.

The of study (Abu Hashish, 2009) aims at examining the effect of the organizational culture on the knowledge management at Al-Azhar University in Gaza by using the descriptive and analytical approach so as to achieve the objectives of the study. The study findings state a number of results, including: "(1) The working staff at Al-Azhar University in Gaza suffer from a lack of sufficient and adequate level of the required knowledge and culture regarding the organizational structure significant enchasing effect. (2) The weakness of programs that encourage both entrepreneurship and leadership. Consequently, the study states the following recommendations: Firstly, It recommends on the pressing need of working on enhancing the organizational culture, creativity, democracy, and the use of different means of motivation for that encourage the working staff to adopt all of these elements of enhancement. Secondly, it stressed on ensuring the compliance with the ethical conduct; in addition to the professional and social values among employees to enhance the organizational culture. The third recommendation stressed on encouraging the professional opportunities leading to improve the level of the academic staff, which contributes to raise the confidence and reduce the level of work-related stress.

However, (Al-Amian, 2002) defines the organizational structure as "the frame and shape of the administrative hierarchy of the organization that demonstrates the job location and its administrative relations and ties among individuals. He also identifies the authority hierarchy and responsibility within the organizational structure. Hence, the viewer of the organization structure can identify the departments, units, responsibilities, authorities, and powers of the institution". Also, (Al-Amian, 2002) states that "the organizational structure is a formal mechanism through which the organization is managed by defining the hierarchy of powers; as well as determining the ways of communication between the 
managers and the working staff. In addition, he defines it as a system for the authority, the accountability and the relationship between organizational units".

Therefore, a study by Akili (Akili, 1996), defines the organizational structure as a framework that illustrates the divisions, units or departments that make up the organization; arranged in the form of levels above each other, and take the form of a pyramid that linked with an official authority. Hence, the official authority provides orders, instructions, and directions from the top level to the lower. This explains the trusted decision-making sources and clears up the authority and responsibility levels.

As well, (Al-Heil'lo, 1985) defines the organizational structure as the organization internal structure that includes all of the organizational constituent divisions. The structure illustrates the relation between these divisions in terms of the decentralization of each one and its components from the lower divisions, its authority, and responsibility. Hence, Al-Heil'lo names the organizational structure with the administrative pyramid.

Similarly, Darwazeh study (2008) titled "The Relationship between the Requirements of Knowledge Management and Process and its Effect on the Excellence of Institutional Performance' 'Applied study on the Ministry of Higher Education in Jordan. The study shows a set of results, which indicate the effect of the relationship between corporate performance and the efficiency of workers, job satisfaction, and workers 'knowledge at the Ministry of Higher Education in Jordan. The study comes with a set of results. These results are:

1. There is a pressing need to amend and develop the organizational and administrative policies in order to enhance the institutional performance.

2. Paying more attention toward the human element that is considered as one of the most productive factors in the organization.

3. Giving priority to the planning process so as to develop the management practices through training and developing managerial skills.

4. Paying more attention toward improving the infrastructure, technology, and providing all of the possible supporting resources in order to provide effective and continuous interaction with the concerned institutions.

Moreover, the study of (Al-Maani, 2009) titled: ' Attitudes of Managers in the Jordanian Central Ministries towards the Role of Knowledge Management on Job Performance'; aims at' identifying attitudes of managers at the central ministries of Jordan towards applying the concept of knowledge management, and towards its impact on their performance.' the researcher uses the descriptive and analytical approach to reach the objectives of his study. However, the aforementioned study states the following findings:

1. Paying more attention to the organizational culture because of its role in encouraging the exchange of information between employees, as well as its eminent role in enhancing the performance and achieving the expected objectives of the organization.

2. The organizational climate plays a major role in the enhancing and developing the performance of the institution and provides appropriate work environment.

3. Managers of the organizations have crucial role in the improvement and development of the institutional performance through the followed policies.

4. Hence, the researcher states a set of recommendations, including the following important ones:

5. Concentrating the efforts toward promoting an organizational culture through encouraging the cooperation and exchange of information.

6. Improving the working environment and granting more authorities for the working staff.

7. Supporting the Intellectual Capital financially and morally through trusted system, which leads to improve performance of the working staff.

In the same respect, the study of (Mintzberg, 1973) states that the application and implementation of administrative processes occupies great importance in achieving and carrying on business and activities of the organization. Thus, the process of management includes decision-making; formulating the objectives, gathering the resources, and using them efficiently and effectively to achieve the organization's growth and stability.

Also, the study (Abu Fa'ra, 2004) titled "Relationship between using Knowledge Management Approach and Performance' 'The study clarifies a set of issues which shows the effect of knowledge and other concepts on performance in the institutions. Thus, the researcher comes out with the following results:

1. The management has an essential role in improving the performance through a set of factors that enhance the 
performance and achievements of the institution like providing the necessary and needed information.

2. The institution 'required performance inputs have leading role in developing and enhancing the performance through using the administrative frameworks; as well as the management functions that lead to reach the drawn goals more efficiently.

3. The organization's leadership has a great role in the success of the institution performance and achieving the drawn goals.

Moreover, the study of (Schermerhorn, 2006) defines the organizational structure in terms of its concept and definition as a framework that identifies the managements, departments, functions, and the hierarchy of authorities of the institution. In addition, it explains the factors that affect designing the organizational structure and the stages of the defectors. Therefore, it illustrates the types of organizational structure and their models and forms. The study also includes the characteristics of the effective organizational structure and its components, and explaining its importance. The study comes out with the following findings: there is a pressing need to have an organizational structure in the business organizations. This structure must be built by referring to the abovementioned criteria. Also, attention must be paid to establish effective organizational structure. Then, the study shows the importance of the organizational structure in the organizing function, which is considered as a foundation stone of the administrative function.

\section{The Hypotheses}

1. The Ministry of Education and Higher Education in Palestinian does not apply the scientific standards in its administrative procedures, decisions, and practices.

2. The Ministry of Education and Higher Education in Palestine does not apply the standards of administration.

3. The Ministry of Education and Higher Education in Palestinian suffers from a lack of qualified and professional working staff, and a lack of competency.

4. There is lack of transparency in the work at the Ministry of Education and Higher Education in Palestine.

5. The Ministry of Education and Higher Education in Palestine does not follow the suitable procedures in taking managerial decisions, decision-making.

6. The Ministry of Education and Higher Education in Palestine does follow the standards of controlling and evaluation procedures and without reference to the rules and controlling requirements.

7. There is no effect for the transparency (high or low) on the institutional performance at the Ministry of Education and Higher Education in Palestine.

8. There is no effect for the management practices (scientific or non-scientific) on the institutional performance at the Ministry of Education and Higher Education in Palestine.

9. There is no effect for the accuracy of procedures, laws, and the administrative programs (accurate or inaccurate) on the institutional performance at the Ministry of Education and Higher Education in Palestine.

10. There is no effect for the availability of the scientific research and developing programs (available or not available) on the institutional performance at the Ministry of Education and Higher Education in Palestine.

\section{The Methodology}

This study is based on the descriptive and analytical approach. The descriptive and analytical approach adopts explaining the phenomena depending on its realty, and considers analyzing and describing the phenomena accurately. The study population consists of 400 employees of the working staff at the Ministry of Education and Higher Education in Palestine including academics and administrators. Similarly, the study sample includes the administrative staff that has a direct link to the formulation and implementation of policies and procedures by the Ministry of Education and Higher Education in Palestine, in the city of Ramallah. This sample represents a random sample that includes 50 employees and rates $\% 12.5$ of the study population. Table (A) shows the study sample distribution by job title.

Table (A). The Distribution of Study Sample by Job Title

\begin{tabular}{|c|c|c|}
\hline Job Title & Frequencies & $\%$ \\
\hline Minister / Deputy / Under-secretary assistant & 2 & $\% 4$ \\
\hline Director & 14 & $\% 28$ \\
\hline Deputy Director & 2 & $\% 4$ \\
\hline Head of Department & 18 & $\% 36$ \\
\hline Employees & 14 & $\% 28$ \\
\hline Total & 50 & $\% 100$ \\
\hline
\end{tabular}


Table (A) explains that the study sample consists of a set of important administrative ranks at the Ministry of Education and Higher Education in Palestine. It shows the ranks percentage of the working staff at the ministry, where (\%28) of them are managers; (\%36) are heads of departments; (\%28) are employees; (4\%) are deputy directors, and (4\%) are minister, deputy, and undersecretary assistant. These percentages show that there is hierarchy and diversity in the positions and ranks, which would help to publicize the results of the study.

However, the following statistical models are employed so as to test the hypotheses of this study. These models are: Descriptive Statistics, Cronbach Alpha Coefficient, and T Test.

Hence, the questionnaire forms were distributed on a number of university lecturers and professors in order to ensure the credibility and stability of the study tool. This also comes to express their views on the appropriateness, level of understanding, and the clarity of the context of the questionnaire form. Consequently, a number of revisions and proposed changes were taken in account. The internal consistency coefficient is 0.95 and rates high, which proves that the questionnaire results match the study procedures.

\section{The Study Results}

The most important outcomes of this study are explained as in the following: -

\subsection{Commitment to Science Standards}

This part of the study comes to test the extent to which the Ministry of Education and Higher Education in Palestine sticks to the science standards in its administrative practices, procedures, and decision-making.

Table 1. The descriptive statistics clarifies the level of commitment to scientific standards in the procedures, decision-making, and administrative practices in the institution.

\begin{tabular}{|c|c|c|c|c|c|}
\hline \# & Item & Mean & $\begin{array}{l}\text { Standard } \\
\text { Deviation }\end{array}$ & Rank & Sig. \\
\hline 1 & $\begin{array}{l}\text { The administrative hierarchy and divisions in the } \\
\text { institution are based on the scientific and } \\
\text { administrative standards and on valid basis. }\end{array}$ & 3.24 & 0.778 & 2 & Medium \\
\hline 2 & $\begin{array}{l}\text { The administrative decisions are based on } \\
\text { appropriate structure and refer to certain specific } \\
\text { term. }\end{array}$ & 3.16 & 1.0279 & 3 & Medium \\
\hline 3 & $\begin{array}{l}\text { The institution decision-making is based on the } \\
\text { centralization. }\end{array}$ & 3.84 & 0.943 & 1 & High \\
\hline 4 & $\begin{array}{l}\text { The decision-making is based on the appropriate } \\
\text { administrative and scientific procedures. }\end{array}$ & 3.12 & 92.73 & 5 & Medium \\
\hline 5 & $\begin{array}{l}\text { There are auditing, revision, and evaluation for the } \\
\text { validity of the procedures of decision-making. } \\
\text { There is also revision of errors, and auditing is } \\
\text { available if any errors occurred. }\end{array}$ & 3.16 & 0.0278 & 4 & Medium \\
\hline
\end{tabular}

Table (1) illustrates that item (3) comes in the first rank and its arithmetic average is (3.84); its standard deviation is (0.943). In contrast, item (1) comes in the second rank and its arithmetic average is (3324); its standard deviation (0.778). We can elicit from the aforementioned data the that the answers of the working staff at the Ministry of Education and Higher Education in Palestine about the commitment to scientific standards in decision-making within various administrative levels is characterized and ranked as adopting centralization in particular. As well, it shows that there is a lack of adherence to the scientific standards when making administrative decisions. Therefore, it states that the review and auditing of decision-making processes need to be paid more attention and efforts by establishing a specialized department to plan and organize auditing and reviewing of decisions and decision-making. It also ensures implementing and achieving the goals and the desired objectives of these decisions, or their failure. Then, working on revising, changing, or cancelling any unsuitable decision when need arises.

At last, item (4) comes in the last rank and its arithmetic average is (3.12); whereas its standard deviation is (0.927). This finding also comes out to confirm that there are a set of problems that are related to the followed methodology in the decision-making. Hence, these problems can be faced by following the scientific and rational administrative standards in decision-making procedures.

\subsection{The Administrative Practices}

This part of the study comes out to examine the extent to which the Ministry of Education and Higher Education in Palestine is committed to the rational administrative practices. 
Table 2. Illustrates the Descriptive Statistics on the Commitment of the Ministry of Education and Higher Education in Palestine to the Rational Administrative Practices.

\begin{tabular}{|c|c|c|c|c|c|}
\hline$\#$ & Item & Mean & $\begin{array}{l}\text { Standard } \\
\text { Deviation }\end{array}$ & Rank & Sig. \\
\hline 6 & $\begin{array}{l}\text { Unofficial works help the administrative function in } \\
\text { the institution. }\end{array}$ & 3.20 & 0.852 & 2 & Medium \\
\hline 7 & $\begin{array}{l}\text { There are training programs, workshops, and events } \\
\text { that clarify the duties and responsibilities towards } \\
\text { developing the administrative work. }\end{array}$ & 3.20 & 0.816 & 4 & Medium \\
\hline 8 & $\begin{array}{l}\text { The unofficial structure helps in enhancing the } \\
\text { administrative function. }\end{array}$ & 2.72 & 0.737 & 5 & Medium \\
\hline 9 & $\begin{array}{l}\text { Relationships outside the institution strengthen its } \\
\text { administrative function. }\end{array}$ & 3.48 & 0.918 & 1 & Medium \\
\hline 10 & $\begin{array}{l}\text { The controlling system in the institution takes part } \\
\text { in supporting and improving the administrative } \\
\text { procedures. }\end{array}$ & 3.24 & 1.06 & 3 & Medium \\
\hline
\end{tabular}

Table 2 proves that item (9) comes in the first rank and its arithmetic average is (3.48); its standard deviation is (0.918). Whereas, item (6) comes in the second rank and its arithmetic average is (3200); its standard deviation is (0.852). However, the abovementioned facts explain the fact that the working staff in the Palestinian Ministry of Education and Higher Education assure that the administrative practices at the ministry are good to some extent. However, these practices need to be developed, reviewed, and revised in order to appropriate the administrative procedures and policies with the contemporary and modern administrative function requirements, which match the changes, and requirements enforced by the internal and external environment.

In contrast, item (8) comes in the last rank and its arithmetic average is (2.72); its standard deviation is 0.737 . This conclusion also confirms that more attention must be given to encourage unofficial relations in order to support and enhance the work and procedures in the institution efficiently. This could be achieved through various means such as supporting morale by encouraging the unofficial positive relations; as well as strengthening cooperation and trust among employees.

\subsection{Competency and Experience}

This part of the study comes to examine the availability of working staff with experience and competency commitment at the Ministry of Education and Higher Education in Palestine.

Table 3. Illustrates the Descriptive Statistics on the Availability of Working Staff with experience and Competency Commitment at the Ministry Of Education and Higher Education in Palestine.

\begin{tabular}{|c|c|c|c|c|c|}
\hline$\#$ & Item & Mean & $\begin{array}{c}\text { Standard } \\
\text { Deviation }\end{array}$ & Rank & Sig. \\
\hline 11 & $\begin{array}{l}\text { Managers and seniors of departments in the institution } \\
\text { have sufficient experience in the administrative work. }\end{array}$ & 3.56 & 1.044 & 2 & High \\
\hline 12 & $\begin{array}{l}\text { There are training programs that are held inside and } \\
\text { outside the institution to provide the working staff with } \\
\text { efficiency and administrative experience. }\end{array}$ & 3.36 & 0.099 & 4 & Medium \\
\hline 13 & $\begin{array}{l}\text { The institution refers to foreign experiences and the } \\
\text { latest administrative developments. }\end{array}$ & 3.36 & 0.994 & 3 & Medium \\
\hline 14 & $\begin{array}{l}\text { The working staff with experience and competency } \\
\text { occupies advanced positions within the institution' } \\
\text { organizational structure. }\end{array}$ & 2.76 & 1.891 & 5 & Medium \\
\hline 15 & $\begin{array}{l}\text { The working staff at the institution own sufficient } \\
\text { experience, skills, and competency in practicing the } \\
\text { administrative and academic activities. }\end{array}$ & 3.64 & 0.907 & 1 & High \\
\hline
\end{tabular}

Table (3) illustrates that item (15) comes in the first rank and its arithmetic average is (3.64); its standard deviation is (0.907). In contrast, item (11) comes in the second rank and its arithmetic average is (3.56); its standard deviation (1.044)). We can elicit from the aforementioned data the fact that the institution needs more competence, skillful and experienced working staff, and offering training programs. Also, the available experiences and competencies at the institution must be used in the optimum and beneficial way. However, item (14) comes in the last rank and its arithmetic average is (2.76); its standard deviation is (1.05). This result also comes to confirm that there is a problem in the optimal use of experiences and human competencies at the institution. The optimal use is through their participants in the 
decision-making at the institution.

\subsection{Transparency}

This part of the study comes out to examine the availabilitylevel of transparency in the work procedures at the Ministry of Education and Higher Education in Palestine.

Table 4. Illustrates Descriptive Statistics Data on the Level Of Transparency in the Work Procedures at the Ministry of Education and Higher Education in Palestine.

\begin{tabular}{clcccc}
\hline$\# \quad$ Item & Mean & $\begin{array}{c}\text { Standard } \\
\text { Deviation }\end{array}$ & Rank & Sig. \\
\hline $\mathbf{1 6}$ & $\begin{array}{l}\text { There are ambiguity and non-disclosure regarding the } \\
\text { process of decision-making in the departments of the } \\
\text { institution. } \\
\text { The procedures of attracting and employing qualified } \\
\text { and professional employees in the institution are } \\
\text { characterized within the transparency and } \\
\text { qualification standards. }\end{array}$ & 3.72 & 0.842 & 1 & High \\
$\mathbf{1 8} \begin{array}{l}\text { There is a clear transparency in the hierarchy of the } \\
\text { administrative procedures in the institution. }\end{array}$ & 3.16 & 0.943 & Medium \\
$\mathbf{1 9} \begin{array}{l}\text { There is administrative corruption in the processes of } \\
\text { implementing the various administrative procedures. } \\
\text { There is transparency in the process of taking } \\
\text { procedures regardless the administrative hierarchy of } \\
\text { the decision. }\end{array}$ & 3.08 & 0.996 & 3.00 & 0.866 & Medium \\
$\mathbf{2 0}$
\end{tabular}

Table (4) illustrates that item (16) comes in the first rank and its arithmetic average is (3.72); its standard deviation is (0.842). In contrast, item (18) comes in the second rank and its arithmetic average is $(3,16)$; its standard deviation (0.943). We can elicit from the aforementioned data that the answers of the working staff at the Ministry of Education and Higher Education in Palestine assure that there are some irregularities in respect to a set of issues like decision taking and the administrative procedures.

At last, item (17) comes in the last rank and its arithmetic average is (2.92); whereas its standard deviation is (1.11505). This finding also comes out to confirm that there is a problem that is related to the followed methodology in the decision-making and procedures as a result of the ambiguity and lack of clarity in terms of the requirements and hierarchy of administrative function requirements.

\subsection{Decision-making}

This part of the study comes to examine the extent to which the Ministry of Education and Higher Education in Palestine follows the right procedures in the process of administrative decision-making.

Table 5. Illustrates the Descriptive Statistics Regarding the Extent to Which the Ministry of Education and Higher Education in Palestine adopts the Right Procedures in Administrative Decision-Making.

\begin{tabular}{|c|c|c|c|c|c|}
\hline$\#$ & Item & Mean & Standard Deviation & Rank & Sig. \\
\hline 21 & $\begin{array}{l}\text { The decision-making process is based on scientific } \\
\text { principles that take into account the modern and latest } \\
\text { developments in the administrative procedures. }\end{array}$ & 3.12 & 0.927 & 2 & Medium \\
\hline 22 & $\begin{array}{l}\text { The latest developments in the Palestinian and } \\
\text { external labor market are taken into account with } \\
\text { respect to educational outputs. }\end{array}$ & 3.20 & 0.763 & 1 & Medium \\
\hline 23 & $\begin{array}{l}\text { All of the administrative levels in the institution } \\
\text { participate hierarchically before making decisions. }\end{array}$ & 3.04 & 0.734 & 4 & Medium \\
\hline 24 & $\begin{array}{l}\text { There is coordination among the Ministry of } \\
\text { Education and Higher Education, universities, and } \\
\text { institutions regarding the educational outputs. }\end{array}$ & 3.08 & 0.759 & 3 & Medium \\
\hline 25 & $\begin{array}{l}\text { There is coordination between the Ministry of } \\
\text { Education and Higher and the institutions of both } \\
\text { public and private sectors in order to train and employ } \\
\text { the manpower. }\end{array}$ & 2.88 & 0.971 & 5 & High \\
\hline
\end{tabular}

Table (5) illustrates that item (22) comes in the first rank and its arithmetic average is (3.200); its standard deviation is (0.76). Then, item (21) comes in the second rank and its arithmetic average is $(3,12)$; its standard deviation $(0.92)$. These findings show that the required procedures of the administrative decision-making in the institution are not always followed.

In contrast, item (25) comes in the last rank and its arithmetic average is (2.88); whereas its standard deviation is (0.97). This finding also comes out to confirm that is an urgent need to improve the followed methodology in the 
decision-making by taking the required administrative procedures.

\subsection{Monitoring and Evaluation}

This part of the study comes to examine the extent to which the Ministry of Education and Higher Education in Palestine applies the assessment and controlling standards by following the requirements and procedures of monitoring.

Table (6) illustrates that item (29) comes in the first rank and its arithmetic average is (3. 56); its standard deviation is (860.). However, item (26) comes in the second rank and its arithmetic average is $(3,16)$; its standard deviation $(0.94)$. These findings show that the assessment and controlling procedures in the institution need upgrading and monitoring in accordance with the modern controlling and administrative regulations requirements.

In contrast, item (28) comes in the last rank and its arithmetic average is (2.72); its standard deviation is (73.). This result also comes out to assure that there is a problem in the followed controlling system. Hence, the concerned officials and parties must pay more attention toward improving the controlling system as it has a major importance in enhancing organizational performance; as well as enhancing the administrative functions through comparing the prepared plans and the recent performance of the institution.

Table 6. Illustrates the Descriptive Statistics Regarding The Extent to Which The Ministry of Education and Higher Education in Palestine Follows the Assessment And Controlling Procedures in Accordance with the Standards and Controlling Requirements

\begin{tabular}{|c|c|c|c|c|c|}
\hline$\#$ & Item & Mean & Standard Deviation & Rank & Sig. \\
\hline 26 & $\begin{array}{l}\text { There are evaluation, controlling, and monitoring } \\
\text { procedures by the Ministry of Education and Higher } \\
\text { Education for the educational programs and their } \\
\text { outputs in the educational institutions of both the public } \\
\text { and private sectors. }\end{array}$ & 3.16 & 0.943 & 2 & Medium \\
\hline 27 & $\begin{array}{l}\text { The educational programs in schools and universities are } \\
\text { revised and corrected; others are canceled which no } \\
\text { longer are needed or do not comply with the market } \\
\text { needs. }\end{array}$ & 2.72 & 0.645 & 4 & Medium \\
\hline 28 & $\begin{array}{l}\text { There are studies and statistics dealing with the needs of } \\
\text { the Palestinian labor market of employment and jobs } \\
\text { vacancies, which are used to review and evaluate the } \\
\text { current and future policies. }\end{array}$ & 2.72 & 0.737 & 5 & Medium \\
\hline 29 & $\begin{array}{l}\text { There is cooperation and coordination between the } \\
\text { government educational institutions and different } \\
\text { international institutions and other countries to take } \\
\text { advantage of the foreign experience in the educational } \\
\text { and administrative fields. }\end{array}$ & 3.56 & 0.869 & 1 & High \\
\hline 30 & $\begin{array}{l}\text { The monitoring and evaluation procedures are done } \\
\text { periodically and in professional and transparence way. }\end{array}$ & 3.0000 & 0.912 & 2 & Medium \\
\hline
\end{tabular}

\section{Hypotheses Testing}

This part of the study comes to discuss study hypotheses as in the following:

Firstly: The first hypothesis states that there is no significant effect for transparency (high or low) on the institutional performance at the Ministry of Education and Higher Education in Palestine. However, to answer this hypothesis, the study used T-test in order to identify the impact of the commitment to the transparency and professionalism by the institution on the level of the performance. Hence, table (7) comes to explain this finding.

Table 7. Results of Testing the First Hypothesis

\begin{tabular}{cccccc}
\hline Mean & N & Degree of Freedom DF & Calculated T & Sig & The Result \\
\hline 3.17 & 50 & 98 & 2.02 & 3.050 & Statistically significant \\
\hline
\end{tabular}

Table (7) shows that the arithmetic average is (3. 17); where T value is (2.03), SIG. value is $(0,35)$. Hence, these findings state that there is a lack of satisfaction and rejection by the working staff on the level of commitment to transparency and professionalism, which then affects the performance and achievements levels in the institution negatively.

Secondly: The second hypothesis states that there is no significant effect for the administrative practices (scientific or non-scientific) on the institutional performance at the Ministry of Education and Higher Education in Palestine. However, to answer this hypothesis, the study used T-test in order to determine the effect of the unofficial relations at the Ministry of Education and Higher Education on the performance level. Hence, table (8) comes to explain this finding. 
Table 8. Results of Testing Hypothesis 2

\begin{tabular}{cccccc}
\hline Mean & N & Degree of Freedom DF & Calculated T & Sig & The Result \\
\hline 3.19 & 50 & 98 & 3.07 & 0.05 & Statistically significant \\
\hline
\end{tabular}

Table (8) shows that the arithmetic average is (3. 19); where T value is (3.07), SIG. value is (0, 05). Hence, these findings state that the unofficial relations among the working staff do not support the official work as required. This affects the performance and the achievements levels in the institution negatively.

Thirdly: The third hypothesis states that there is no significant effect for the accuracy of the administrative procedures, programs, and laws (accurate or inaccurate) on the institutional performance at the Ministry of Education and Higher Education in Palestine. Hence, to answer this hypothesis, this study uses T-test in order to identify the effect of the administrative procedures, programs, and laws on the performance levels at the institution. Table (9) comes to explain this finding.

Table 9. Results of Testing the third Hypothesis

\begin{tabular}{cccccc}
\hline Mean & N & Degree of Freedom DF & Calculated T & Sig & The Result \\
\hline 3.30 & 50 & 98 & 3.02 & 0.00 & Statistically significant \\
\hline
\end{tabular}

Table (9) shows that the arithmetic average is (3.3); where T value is (3.02), SIG. value is (0, 00). Hence, these findings show that there is a need to alter and modify the followed procedures and practices; in addition to some of the laws that hinder the achievement of the efficiency in the administrative work which will affect the performance and levels of achievements in the institution. Here we must point out that there is an urgent need for a continuous development for the procedures, laws, and regulations in a way that matches the changes and developments that becomes a major feature of the current business environment.

Fourth: The fourth hypothesis states that there is no significant effect for the availability of the scientific and developing research programs (available or not available) on the institutional performance at the Ministry of Education and Higher Education in Palestine.

Hence, to answer this hypothesis, this study uses T-test in order to identify the effect of the availability of scientific and developing research programs on the performance levels at the institution. Thus, table (10) comes to explain this finding.

Table 10. Results of Testing the Fourth Hypothesis

\begin{tabular}{cccccc}
\hline Mean & N & Degree of Freedom DF & Calculated T & Sig & The Result \\
\hline 3.36 & 50 & 98 & 2.04 & 0.05 & Statistically significant \\
\hline
\end{tabular}

Table (10) shows that the arithmetic average is (36.3); where T value is (2.04), SIG. value is (0, 05). Hence, these findings show that there is a pressing need to do more scientific research in order to develop and correct the administrative function. As well, there is a need to increase the administrative efficiency at the Ministry of Education Higher Education in Palestine, which would bring a positive impact on the performance and achievement levels in the institution. Additionally, it leads to modify the negative behaviors and enhance the positive ones at all administrative levels at the Ministry of Education and Higher Education in Palestine.

\section{The Results}

The following are the most important results of this study.

- The planning procedures of the academic and administrative functions suffer from weaknesses and deficiencies regarding the current and future programs.

- The educational outputs created a gap between the market requirements and the current administrative and academic programs on the local and regional level.

- There is a lack of adequate controlling and domination by the Ministry and its official departments over the administrative functions and academic activities at various academic institutions.

- The educational and academic outputs suffer from insufficient commitment and using of the modern administrative and academic standards.

- There is a weakness in the coordination between the Ministry of Education and Higher Education and the educational institutions of both the public and private sectors in Palestine.

- There is a lack of enough cooperation in organizing the educational programs for various educational stages starting from the primary stage and ending with the university graduation.

- Various decision-making procedures that are related to the educational policies and procedures are applied without 
enough and thoughtful studying; wherein the centralization dominates over the process of decision-making.

- There is a lack of enough follow-up and controlling regarding the implementation of various academic and administrative programs, which leads to a deviation in achieving the drawn goals and plans.

- There is a lack of sufficient and organized evaluation through which we can recognize the advancement in achieving the drawn goals; as well as the decisions and functions are being corrected and revised in order to serve the organization and its drawn goals.

- There is a clear inaccuracy and failure regarding the development, the construction, and creation of the educational and academic programs of different educational stages. This affects the latest needed requirements of the work environment and in a way, that does not match the data and the developments of the work internally and externally.

- There is a lack of sufficient coordination regarding the educational outputs between the academic and educational institutions of both sectors the public and the private.

Based on the previous findings, the study comes out with the following recommendations:

- The Ministry of Education and Higher Education in Palestine is advised to focus on the importance of increasing the coordination between the educational institutions and the governmental organizations regarding the planning and the implementation of the current and the future lesson planning programs.

- It highly recommends the government to increase its role in terms of planning, implementation, supervision, and reviewing the different educational and academic programs.

- There is a pressing need to give the priority to employ the qualified specialists and experts who can establish and develop the programs and the academic curricula and other educational specializations. This step will help in building, modifying, and providing different educational programs and specializations in order to offer the needed and contemporary academic majors.

- There is a vital importance for increasing the role of the government and the Palestinian civil society institutions in the supervisory and controlling procedures in order to revise and correct the policies and procedures related to the improvement of the institutional performance of the institutions and their branches in Palestine.

\section{References}

Abbas, B. (2001). Principles of Science Management, Al-Raed Scientific Library, Amman, Jordan.

Adnan, H. (2015). Effect of Organizational Culture, Organizational Commitment to Performance: Study in Hospital Of District South Konawe of Southeast Sulawesi. The International Journal of Engineering and Science (IJES), 4(5), 33-41.

Akili. (1996). The Management Is Principles and Concepts, Dar Zahran for Publication, Amman, Jordan.

Akili, A., \& AL-Mo'min. (1994). The Organization and Organizing Theory, Dar Zahran for Publication and Distribution, Amman, Jordan.

Al-Emian, A. (2002). The Organizational behavior in Business Organizations, First Edition, Dar Wael for publication, Amman, Jordan.

Al-Heil'lo. (1985). Science of Public Administration, Dar Al-Jame'a for publication, Alexandria, Egypt.

Al-Jaw'hari. (1985). Principles of Administration and Management, Dar Al-E'sha'a for publication printing, Cairo, Egypt.

Al-Ma'ani. (2009). Trends of Managers at the Jordanian Ministries and Centers towards the Role of Knowledge Management in Work Performance.

Al-Qaryouti. (1997). The Organizational Behavior, Second Edition, Amman, Jordan. An Introduction to Management Umm Al Qura University, Kingdom of Saudi Arabia.

Darwazeh. (2008). The Relationship between Knowledge Management Requirements and their Operations and their Impact on the excellence of the Organizational Performance, Applied Study in the Jordanian Ministry of Education and Higher Education.

Ebert, R., \& Griffin, R. (2009). Business Essentials, Ninth Edition, Pearson Prentice Hall.

Esra, A. I. C., \& Mithat, K. (2011).The Effect of Organizational Culture on Organizational Efficiency: The Moderating Role of Organizational Environment and CEO Values. Procedia - Social and Behavioral Sciences, 24, 1560-1573. http://dx.doi.org/10.1016/j.sbspro.2011.09.092

Fakhar, S., Rana, A. L., Ayesha, R. K., \& Lalarukh, S. (2012). Impact of Organizational Culture on Organizational 
Performance: an Overview. Interdisciplinary Journal of contemporary research in business, 3(9), 975-985.

Schermerhorn, J. R. (2006). Introduction to Management, Mc GRAW-HILL, International Edition.

Juris, I., Viktorija, S., \& Gaile-Sarkane, E. (2016). Impact of Organizational Culture on Organizational Climate during the Process of Change. Procedia - Social and Behavioral Sciences, 213, 944-950.

Ministry of Education and Higher Education. (2005). Education for All, the Future Action Framework (2015/2005). Ramallah, Palestine.

Mintzberg, H. (1973). The Nature of Managerial Work, New York, Harbor and Row.

Palestinian Central Bureau of Statistics. (2005). Database of Education Survey 2004-2005. Ministry of Education and Higher Education. Ramallah - Palestine.

Palestinian Central Bureau of Statistics. (2009). Database of Education Survey for the academic year 2007/2008 Ministry of Education and Higher Education. Ramallah - Palestine.

Palestinian Central Bureau of Statistics. (2011). Annual Report -2011. Children of Palestine - Issues and Statistics.

Palestinian Central Bureau of Statistics. (2011). Palestinian Household Survey, 2010. Main Report- RamallahPalestine.

Palestinian Central Bureau of Statistics. (2012). Database of Education Survey for the academic year 2010/2011 Ministry of Education and Higher Education. Ramallah - Palestine.

Quan'suah, \& Rashid. (1984). The Administrative Management and Systems Analysis, Third Edition, Dar-Alnahda Al Arabiafor Publishing, Cairo, Egypt.

Robin, J. E., Ricky W., \& Griffin, S. (2000). The Theory of Organization Structure and Design, First Edition, Dar Wael for Publishing, Amman, Jordan.

Seyed, A. M., Seyed, Y. H., \& Neda, H. (2015). On the Effects of Organizational Culture on Organizational Performance: An Iranian Experience in State Bank Branches. Iranian Journal of Management Studies (IJMS), 8(1), 97-116. Stephen P Robbins -Mary Coulter -Management- Eleventh Edition -Person Education Limited, 2012.

Sylvie, L. (2016). Effects of organisational culture on organisational innovation performance in family firms", Journal of Small Business and Enterprise Development, 23(2), 379-407.

\section{(c) EY}

This work is licensed under a Creative Commons Attribution 3.0 License. 